\title{
ILCEA
}

Revue de l'Institut des langues et cultures

d'Europe, Amérique, Afrique, Asie et Australie

$45 \mid 2022$

Femme(s) et sorcellerie en Espagne et en Italie à l'époque moderne

\section{Extraños sucesos o la farsa de la brujería popular}

Weird Events or the Farce of Popular Witchcraft

Événements bizarres ou la farce de la sorcellerie populaire

\section{Rocío Alamillos Álvarez}

\section{OpenEdition}

\section{Journals}

Edición electrónica

URL: https://journals.openedition.org/ilcea/14803

DOI: 10.4000/ilcea.14803

ISSN: 2101-0609

Editor

UGA Éditions/Université Grenoble Alpes

Edición impresa

ISBN: 978-2-37747-330-4

ISSN: 1639-6073

\section{Referencia electrónica}

Rocío Alamillos Álvarez, «Extraños sucesos o la farsa de la brujería popular», ILCEA [En línea], 45 |

2022, Publicado el 31 enero 2022, consultado el 31 enero 2022. URL: http://journals.openedition.org/ ilcea/14803 ; DOI: https://doi.org/10.4000/ilcea.14803

Este documento fue generado automáticamente el 31 enero 2022.

(c) ILCEA 


\title{
Extraños sucesos o la farsa de la brujería popular
}

\author{
Weird Events or the Farce of Popular Witchcraft \\ Événements bizarres ou la farce de la sorcellerie populaire
}

\author{
Rocío Alamillos Álvarez
}

1 La superstición estuvo completamente integrada en la vida cotidiana desde las primeras civilizaciones y sobrevivió a pesar de las prohibiciones establecidas durante la Edad Media y Moderna, debido a la función que cumplía en la sociedad. La brujería, en cambio, nunca siguió esta estela. Numerosos estudios han demostrado que este concepto se estableció en Europa de forma acumulativa y progresiva. La resonancia de los discursos demonológicos llegó a las capas populares más bajas de toda Europa. Este resonar encontró sus manifestaciones en algunos capítulos de histerias colectivas que se dieron en Europa y especialmente en la España septentrional durante la primera mitad del siglo XVII ${ }^{1}$. La llegada de estas ideas sobre lo demoníaco fue más propicia en el norte si tenemos en cuenta la cercanía a una Europa que encendía hogueras y recolocaba horcas. El sur, por su parte, continuó con la presencia de las prácticas supersticiosas al uso ${ }^{2}$. Tras la publicación de las instrucciones sobre brujería ordenadas por el inquisidor general Bernardo de Sandoval y Rojas el 29 de agosto de 1614, se exigía mayor rigor en la aceptación de pruebas que demostrasen que una persona era brujo o bruja ${ }^{3}$. Eso supuso que a lo largo del resto del siglo XVII y del siglo xVIII casi desaparecieran las acusaciones en firme de brujería en España. Sin embargo, parte de estos discursos demonológicos se siguieron utilizando ante la Inquisición, como comprobaremos en este trabajo. Es así como el uso interesado y apropiado de los elementos y símbolos del discurso demonológico por parte de individuos envueltos en causas inquisitoriales, es una permanencia en la Edad Moderna. Entre el siglo XVI y XVIII nos encontramos distintos casos donde se realizan usos particulares de los atributos y elementos propios del brujo o la bruja.

2 Con el análisis de dichos casos que ofrecemos a continuación ${ }^{4}$, tratamos de manifestar cómo parte de la población del sur peninsular que recibió "desde arriba" un discurso predeterminado, usó ciertas partes del mismo para aderezar, maquillar o 
esconder fines personales. Se produjo así una apropiación de estos elementos con la intención de esconder otros pecados, crímenes $u$ otras intenciones. De esta forma el discurso demonológico quedó manifiesto mezclado con asuntos propios de la superstitio y elementos mundanos, creándose en determinadas ocasiones un imaginario idiosincrático ${ }^{5}$. La principal motivación para estos usos fue la protección personal, reflejada en tres casuísticas principales: como una vía de escape (de escándalos por desórdenes sexuales, de acusaciones de robo, asesinato, superstición o por miedo a la hoguera); para socorrer sus propias necesidades o como evasión a las presiones de curas y presbíteros.

Hubo, por tanto, dos interpretaciones de la brujería: la erudita y la popular. La primera era la proveniente del mundo religioso, basada en la reflexión y la creación discursiva. Los inquisidores, sacerdotes, confesores y miembros de las órdenes podían aprender a reconocer las prácticas sobrenaturales a través de prontuarios, tratados morales, manuales de confesores y obras dedicadas específicamente a tal fin ${ }^{6}$. En cambio, el pueblo no tuvo tan fácil acceso a este tipo de ilustración. La interpretación y aprendizaje popular estuvo fundamentada en fuentes muy distintas. Destacaron la tradición oral basada en historias contadas en las plazas o a través de conocidos, la asistencia a los autos de fe, las relaciones de autos impresas y difundidas, la información transmitida por párrocos y confesores o los panfletos y estampas. De esta forma se podría decir que la instrucción sobre brujería por el pueblo fue un aprendizaje experimentado, sentido, percibido, en definitiva "vivido" mientras que el de la esfera erudita fue "leído".

4 Dejando las altas esferas atrás y centrándonos en los casos que se daban en la vida cotidiana, una verdadera vía de escape se muestra en dos llamativos casos que sucedieron en la villa cordobesa de Montilla. Desde 1570 los padres jesuitas de la localidad comunicaron a la Inquisición que allí había más de 50 personas ${ }^{7}$ que tenían un familiar8. Los párrocos desde sus púlpitos y confesionarios comenzaron a incitar persistentemente a los feligreses para que se autodelatasen de su trato con lo demoníaco. Ante tales estímulos de salvación saltaron a la palestra dos casos: la acusación de brujo de don Alonso de Aguilar y la autodelación de acudir a aquelarres de Inés de Venegas.

5 Esta, una mujer de 33 años y cristiana vieja, confesó en 1573 actos sobrenaturales acusando a una amiga de la familia, Inés de Cabeza. Según relató la delatora, la Cabezas estaba empeñada en casar a su primo con la Venegas y ella siempre se negó. Durante ese tiempo la Cabezas la engañó y la llevó al mundo diabólico. Según ella relata, le pidió cabellos, trozos de cinta de sus vestidos y alguna joya para conjurarla, probablemente para conseguir su consentimiento en el casamiento. También sospechaba que le dio de comer un nuégado que estaría "aliñado" porque desde ese momento ella solo sentía el deseo de pasar tiempo con Inés de Cabeza. Esta le dijo que la podía llevar dentro de tres o seis horas a Sevilla y para ello le suministró una untura en las palmas de las manos y la delatora dijo quedar vencida y aceptar el casamiento. Esa misma noche, hacia las doce, Inés de Cabezas concertó una cita con los demonios, le untó en distintas partes del cuerpo mientras recitaba palabras que ella no entendió por estar aturdida, después se desnudó y aparecieron tres hombres. Uno era el primo, otro un familiar de Inés de Cabeza y otro sería a partir de entonces el familiar de Inés de Venegas «que la había de llevar sin ser vista y había de renunciar diciendo que renunciaba de Dios y de su madre y de los ángeles y los santos». También le dijo que para poseer este familiar ella debía 
cederle su alma y su cuerpo. Después relató la existencia de aquelarres multitudinarios diciendo «que en Sevilla había doscientos y tantos hombres y ciento y tantas señoras de lustre, sus compañeras que iban a Vizcaya, Navarra y Sevilla». También dijo que habían matado a 120 niños, que hacían cuanto mal podían y que en aquellas reuniones tenían trato carnal con el demonio y sus familiares y no perdían su honor. Acabó su testimonio añadiendo que había estado años ocultando esto porque el demonio la tenía amenazada. Relató que la perseguía cuando iba al confesionario y le daba golpes para que no contara la verdad (Gracia, 1983: 112-115).

No quedan muy claras las verdaderas pretensiones de la delatora al contar estos multitudinarios aquelarres donde confluía gente que viajaba a Sevilla, Navarra y Vizcaya, el desenfreno sexual, los untos y las renuncias al cristianismo. Lo que sí es un hecho es que introducir estos elementos fabulosos la ayudaron a escapar indemne de la situación. En los años anteriores la Inquisición había estado siguiendo la causa de varias acusadas de superstición y habían recibido sentencia y salido a auto público de fe en 1572, justo un año antes de la autodelación de Inés de Venegas. En las villas de alrededor también había práctica de superstición que se sometía a pesquisa. En esta ocasión, con la lectura del edicto de fe se había llegado al acuerdo de ser benevolentes con aquellos que desvelasen sus pecados con verdadero arrepentimiento. La finalidad era que salieran a la luz todos los casos posibles. La población pudo sentirse intimidada por la continua actividad inquisitorial en el entorno geográfico rastreando la práctica mágica.

7 Inés de Venegas aprovechó la situación de condescendencia anunciada por el Santo oficio, decidió delatarse voluntariamente y quizá por eso no entró en prisión. Acusó a la amiga de la familia de llevarla a ese oscuro mundo y después se defendió diciendo sentirse amenazada y ultrajada por el demonio para permanecer en silencio todos estos años. Todo ello unido a la imaginación de los hechos narrados hicieron que la Inquisición le concediera el perdón. No corrió la misma suerte Inés de Cabeza, que no se autoinculpó sino que había sido acusada. Durante la investigación de los hechos sí fue apresada e incluso torturada para descubrir la veracidad de aquello que narró Inés de Venegas, aunque tras perseverar en su negativa también fue absuelta. No queda reflejado en la documentación la causa por la que decidió contar hechos tan rocambolescos. Se pueden contemplar muchas posibilidades, como que existieran rencillas personales con otros vecinos del pueblo y ella quisiese evitar la posibilidad de ser acusada de prácticas de hechicería o brujería. Si ella misma acudía a la Inquisición con anterioridad y confesaba se aseguraba un trato benévolo. Al inventarse capítulos tan disparatados sobre el demonio, las reuniones y los vuelos era más fácil que considerasen que solo eran imaginaciones y no le diesen mayor importancia, consiguiendo así una pena leve o incluso resolver el asunto con una reprimenda. Finalmente la estrategia resultó un éxito.

8 El segundo caso que se dio en Montilla de forma paralela fue el relacionado con la investigación de la figura de don Alonso de Aguilar, que había sido acusado de brujería. La situación de tensión marcaba la vida en todo el entorno geográfico. La práctica supersticiosa y de hechicería rebosaba en aquella villa. Se estaba siguiendo causa desde 1570 a varias mujeres acusadas de hechicería entre las que estaba la Camacha. Igualmente se habían estado investigando los supuestos conventículos, untos y brujerías a los que se refería Inés de Venegas. Además los padres jesuitas de la zona aseguraban a los inquisidores que había más de 50 personas con familiar en aquellas 
tierras y que se realizaban artes oscuras. Con todo este escenario montado Luisa de Gálvez y Marina Brizuela ${ }^{10}$ movidas por el consejo de su confesor acusaron en 1570 a don Alonso de Aguilar, pariente del marqués de Priego, hijo de Pedro Núñez de Herrera, de brujo, de tener familiar, compañeros del arte y realizar multitud de herejías en relación con mundo mágico. Mientras el proceso de don Alonso estaba siendo investigado llegó al Consejo de la Suprema la noticia de que en Córdoba y sus villas, especialmente en Montilla "se han descubierto ciertas cosas tocantes a brujas o mágicas» (Gracia, 1984: 155). Tras esta nueva información volvieron a llamar a declarar a Marina Brizuela y a su hermana María Magdalena y esta última comenzó a dar numerosos nombres nuevos y a relatar otros hechos que antes no había referido.

9 La situación fue tal que la Suprema Inquisición envió como inquisidor a Andrés de Álava en sustitución del licenciado Antonio Santos para profundizar en estos asuntos. La nueva tríada inquisitorial siguió investigando las causas acumuladas. En febrero de 1575 recibieron la delación voluntaria de María de la Encarnación, hija de Andrés de Morales y vecina de Córdoba, que acusó a numerosas personas de practicar el arte mágico y de pacto con el demonio. Entre ellas hizo especial referencia a don Alonso de Aguilar y a Teodoro Chirinos, mozo del marqués de Priego. Se ordenó entonces la búsqueda inmediata de libros y papeles de tema mágico tanto en Córdoba como en Montilla y Priego ${ }^{11}$.

10 Como el asunto de don Alonso de Aguilar se estaba dilatando en exceso y seguían saliendo nuevos testigos que lo involucraban una y otra vez, la Suprema decidió sustituir al inquisidor Andrés de Álava por el licenciado Álvaro de Reinoso que acudiría a Montilla con el único objetivo de resolver dicho caso y las causas de Brizuela y su hermana. El inquisidor Reinoso se encontró con nuevas sorpresas. En el proceso contra Isabel Hernández, la Lozana, se hacía referencia a juntas diabólicas, a las que acudió un hombre llamado Alonso de Gaete con un libro de conjuros que había pasado de mano en mano desde Granada (Gracia, 1984:158). Cuando interrogó en persona a Isabel Hernández la Lozana, Marina de Brizuela y María Magdalena, estas siguieron fabulando sobre lo ya confesado, implicaron a nuevas personas y dieron numerosos detalles de los aquelarres de brujas, asegurando que se realizaban en ciudades andaluzas como Sevilla, Málaga, Granada y Jaén pero también en otras zonas de España como Salamanca o Valladolid. También se acusó al clérigo Cristóbal de Lucena de acudir a las juntas de brujas y brujos y se recogió que un vecino de Villafranca dijo ver una noche cómo se llevaban a dos mujeres volando, que no regresaron a su casa hasta la mañana siguiente (Gracia, 1984: 159).

11 Álvaro de Reinoso, enviado para cerrar este asunto, se encontró con un proceso que a su vez abría nuevos procesos y pesquisas a gran velocidad. El trabajo se acumulaba, las causas no se aclaraban y la fantasía "volaba" sobre el territorio montillano y su entorno.

12 El doctor Alonso Gómez realizó una visita el 14 de septiembre de 1575 expresamente a Montilla y villas cercanas para tratar de ayudar en la resolución de este fantasioso foco. El resultado de esta visita fue la acusación de Juana Ruiz, una beata acusada de tener trato carnal con el demonio, y un listado de acusadas de hechicería y brujería (Gracia, 1984: $164-166)^{12}$.

13 En 1576 las dos hermanas, embusteras y fantasiosas, volvieron a realizar nuevas declaraciones que inculpaban a don Alonso de Aguilar y Teodoro Chirinos y al alcaide de las cárceles secretas, su ayudante y a un despensero. La situación era ya tan 
rocambolesca que los inquisidores estaban desesperados por darle un final y resolver la verdad de todo este asunto. Para ello se solicitó dar tormento a las hermanas y a María de la Encarnación que acabaron confesando que se habían inventado todas estas cosas contra don Alonso porque habían oído decir que trataba con Luisa de Gálvez, que se hacía conocer como hechicera. Ya en el interrogatorio del 28 de enero de 1577 María Magdalena confesó que había inventado todas aquellas acusaciones, hechos y personas implicadas y que tenía temor a la hoguera. Dijo que la insistencia de preguntas e interrogatorios la llevaron a inventar nuevas mentiras y que en cierto momento sintió que no podría desdecirse por temor a la pena que pudiera recibir. También pensaba que jamás saldría viva de aquellas cárceles, por lo que continuó adelante con aquella versión fabulosa que estaba creando con el paso de los años ${ }^{13}$.

14 A través de este enrevesado caso queda reflejado cómo en ocasiones la figura del confesor tomaba cierto control sobre la conciencia de sus feligreses. En sus momentos de confesión este podía intuir que algunas prácticas de sus confidentes fueran inapropiadas y más cercanas a lo demoníaco que a lo divino. Estos confesores crédulos conseguían que mujeres como Luisa de Gálvez, Marina Brizuela o María Magdalena no tuvieran malestar de conciencia y las inducía a delatarse a sí mismas ante la Inquisición. Por otro lado, la técnica del interrogatorio inquisitorial generaba miedos que podían complicar los resultados de las investigaciones. Los individuos, temerosos de lo que les pudiera ocurrir, acaban embarcándose en la narración de historias ficticias, respondiendo a las encadenadas preguntas que les hacían los inquisidores. Con el empeño de estos en desgranar la información hasta llegar a la raíz del asunto, se ejercía presión en los acusados, que acababan enredando aún más la versión de los hechos. Esta es la razón por la que en un contexto donde no era común la acusación de brujería, surgió un sumario tan escandaloso como este.

Un caso similar tuvo lugar entre 1645 y 1646 en Rute, vecindad cordobesa. María Jiménez de 16 años y apodada María la de Burgos se autoinculpó admitiendo ser una bruja y confesó que formaba parte de una secta de brujos en dicha localidad. Dio todo tipo de detalles sobre sus miembros y acciones comenzando por delatar a Beatriz Páez, vecina del lugar y maestra o líder de la comunidad de brujos. Dicha maestra fue la que insistió una y otra vez para introducirla en la congregación. En sus confesiones dio los nombres de los demás miembros de la secta, siendo estos Luisa la hija de la maestra Beatriz Páez, Ana Gómez, María Quesada y Francisco Ramos el zángano ${ }^{14}$. Narró cómo a menudo se reunían y tocaban instrumentos y bailaban al son de las sonajas y tamboriles. También relató que una vez se desplazaron hasta Iznájar y para ello primero fueron a un lugar donde les esperaba un demonio con la cara encendida en fuego y vestido de negro. A continuación se desnudaron quedando solo con una camisa y la maestra los untó con un ungüento en axilas, ingles y sienes para prepararse para volar por los aires hasta Iznájar. Habiéndose formado una gran nube negra cada uno de ellos hizo el vuelo acompañado de dos demonios a su lado, uno en forma de caballo y otro en forma humana, mientras el demonio de cara encendida custodiaba sus ropas. Al llegar a la villa hicieron algunos males y bailaron al ritmo de la música. A su regreso a Rute acabaron la reunión con trato carnal con los diablos de forma humana que les habían acompañado y María de Burgos describió cómo después le besaban las partes traseras al demonio. Sin embargo esta no fue la única salida nocturna que refirió, también describió otras realizadas a cultivos con la intención de dañarlas. Para rematar 
el estereotipo de brujería, también relató que en una ocasión habían causado la muerte de una niña de un año y medio a pellizcos ${ }^{15}$ (Coronas, 1995: 11-35).

Los a priori inexplicables relatos fantasiosos de esta mujer encuentran su completo sentido cuando se profundiza en su causa y su biografía. María Jiménez era una mujer que llegó a la campiña cordobesa desde Burgos, lugar de procedencia. Sus testimonios presentan numerosos paralelismos con algunos de los capítulos de los procesos de Logroño contra los brujos vasco-navarros. Entre la cercanía de la región a Logroño, la popularidad de los procesos de 1610 y la difusión posterior con las reediciones por escrito del Auto de fe, María tuvo sin duda conocimientos de los relatos que los implicados fueron detallando ${ }^{16}$ (Coronas Luis, 1995: 11-35). Su discurso era de manual de demonología.

La razón subyacente que hizo a esta pícara testificar tales atrocidades e inverosimilitudes fue que había sido apresada por la justicia real, acusada de robo en la casa donde prestaba sus servicios. Para evitar ser procesada por dicha vía, que implicaría una pena mayor, repentinamente quiso confesar todos estos hechos para limpiar su conciencia. Casualmente así la presa lograría evadir la justicia ordinaria y habida cuenta de los extraordinarios hechos que aseguraba haber vivido pasaría a ser juzgada por un delito de fe por la Inquisición, que sin duda le trataría con mayor benignidad. A eso le añadimos que hacia el final de su proceso, estando en las cárceles secretas, dijo haber tenido una visión de la Virgen María que se le apareció con un manto blanco rodeada de un gran resplandor. María repite este patrón que ya tuvo lugar en los casos de brujería vasco-navarra, donde los acusados aseguraban haber tenido apariciones de la Virgen con los que habían roto su subordinación al demonio y habían regresado al seno del cristianismo ${ }^{17}$. Los inquisidores cordobeses trataron a María Jiménez más como una embustera y farsante que como una verdadera bruja rescatada por la Virgen. Se la condenó a prisión atenuada, quizá por haberse delatado espontáneamente ${ }^{18}$.

18 Continuando con el análisis de casos, en torno a 1743 comenzó a investigarse un escandaloso caso que tuvo lugar en el seno del convento de Santa Clara de Antequera, Málaga $^{19}$. En él estuvieron implicadas varias monjas aunque las dos que tuvieron un papel más relevante fueron doña Rosa Montilla y doña María Montero de los Dolores ${ }^{20}$. Las demás cómplices fueron: sor María Josefa Casasola, su hermana sor Josefa María Casasola, sor María de San Rafael Losada y su hermana Ángela de la Santísima Trinidad Losada, la lega María de la Concepción, sor Josefa de Torres, doña Antonia Zarco compañera de celda de doña María de San Rafael Losada, María Díaz y Alonso Osuna. A todas estas personas se les tomó declaración llegando a tejerse entre todos los testimonios una red de acontecimientos extraordinarios que poco tenían que ver con una vida ordenada y de rezos.

En el testimonio ofrecido por doña Rosa Montilla se supo que esta monja formaba parte del coro del convento. Con el beneplácito de su prelada bajaba cada día a un locutorio junto a otras monjas de la orden para tomar lecciones de música con Alonso de Osuna, un mozo soltero de oficio organista y barbero. Dicho mozo parece que dejándose llevar por la lascivia tenía tocamientos con algunas de estas monjas, que aseguraban que aparecía en el convento por arte del demonio y de forma inexplicable.

Otra de las hermanas, doña María de los Dolores Montero, presentaba ciertas heridas en el pecho que se reabrían en ciertas ocasiones y que fueron interpretadas como marcas de pacto con el demonio ${ }^{21}$. El 31 de marzo de 1764 se delató voluntariamente, aunque 
inducida por su confesor fray Agustín Ponce, afirmando como su compañera, que Alonso de Osuna se le aparecía dentro del convento de clausura por arte del demonio ${ }^{22}$ y que acudía a juntas diabólicas con cómplices como doña María de Ortega, la prelada del convento ${ }^{23}$. Por su parte, en las declaraciones que se tomaron a doña Ángela de la Santísima Trinidad Losada, consta que esta dio noticia de que en el convento se custodiaban libros de temas mágicos en los que se asentaba la "cofradía del demonio" 24 . Este testimonio fue reforzado por sor María de San Rafael que acusó a doña Rosa Montilla de custodiar algunos de esos ejemplares en su celda.

21 Pero si hubo alguna religiosa que destacara más que las demás por adoptar un discurso propio de la brujería, esta fue doña María de San Rafael Losada. Confesó al comisario Zenzano que «en estos últimos años eran cada día más frecuentes las juntas diabólicas, aunque la última noticia que le ha comunicado ha sido que ya no continuaban con frecuencia» ${ }^{25}$, no obstante a esas alturas el demonio ya había perturbado la orden religiosa. De estas juntas diabólicas también dieron cuenta las hermanas Casasola además de Josefa Torres y María de los Dolores Montero ${ }^{26}$. Parecía que todas estuvieran de acuerdo en haber vivido esas experiencias o conocer que se daban en el seno de la orden.

Losada realizó declaraciones a lo largo de los años donde los datos que aportaba venían a enredar aún más el discurso demonológico que estaba construyendo, completando y complicando hechos narrados previamente y aportando otros nuevos. Su primera declaración tuvo lugar el 10 de septiembre de 1764 donde delató a cuatro cómplices que concurrieron en las juntas diabólicas y reconoció que ella acudió a estas congregaciones en el año 1761, teniendo por aquel entonces 13 años $^{27}$. En la versión que dio al año siguiente, en 1765, implicó a muchas más personas, tanto religiosas como religiosos y personas de otros estados. Llegó a decir que habían sido tantos los participantes que se le había olvidado, pero que eran religiosas incluso de órdenes de otros pueblos con quienes supuestamente compartió las reuniones a las que acudió.

En dicha delación dijo «que para salir por arte diabólico no procedía sino es el convenio y consentimiento de las que querían salir a volar [...] para tales salidas precedían unturas como que eran preciso requisito» ${ }^{28}$. También declaró en 1764 haber pactado con el demonio quedando reflejado en una cédula. Al año siguiente, en 1765, expresó que la firma del pacto la hizo con la sangre de la herida de su propio pecho. Posteriormente añadió que en varias ocasiones en los aquelarres le abrieron a la fuerza y con violencia la herida ${ }^{29}$.

24 En declaraciones del 3 y 25 de octubre de 1765 dijo que los desórdenes y escándalos fueron aumentando en frecuencia y en número de personas implicadas tanto de dentro como de fuera del convento ${ }^{30}$. También dijo que en las juntas diabólicas la persuadieron para que renegara de los misterios católicos y para que adorara al demonio en figura de Alonso de Osuna hincándose de rodillas ante él. Durante los años 1762, 1763 y 1764, hasta que llegó el visitador, continuaron estos encuentros con el demonio teniendo comercio carnal con él tanto en figura de Alonso de Osuna como de perro. Según la versión de los hechos de la propia María de San Rafael Losada, hasta 36 monjas realizaron tales actos, describiendo la declarante todo detalle y circunstancias.

En sus amplias declaraciones dejó constancia de otros asuntos como que en la comunidad había una ciega subordinación al demonio por parte de religiosas y religiosos tanto de la localidad como de forasteros. También desveló que varias religiosas a las que no había nombrado antes parieron bebés ${ }^{31} \mathrm{y}$ dichas acusaciones no 
fueron aisladas ya que el propio Alonso de Osuna afirmó que en el convento había fama de que las religiosas trataban carnalmente con hombres «y salían muchachos de las monjas como cestillos» ${ }^{32}$. También doña María de San Rafael hizo saber que en el convento había unos ungüentos, que tras ser examinados por el Santo oficio se calificaron de ser «aptos para fines supersticiosos» ${ }^{33}$.

Durante años se siguió investigando el extraño caso acontecido en esta orden y el inquisidor fue obteniendo ciertas respuestas que podían explicar la composición de este discurso tan singular. María de los Dolores Montero reveló al confesor oficial de las religiosas, fray Agustín Ponce, los sentimientos y cavilaciones que tenía en su mente y este, un hombre crédulo como ninguno comenzó a persuadirla de que lo que ocurría no eran sueños sino realidades. El Inquisidor concluyó que «hostigada la religiosa con tanta insistencia y persecución sobre que dijese por menor todo cuanto la pasaba, que por complacerle fingió de palabra y por escritos en varias cartas cuantos desatinos ofrecían y había leído en varios libros y novelas» ${ }^{34}$. Entre estos desatinos detalló encantamientos, conventículos y todo tipo de ocurrencias y disparates que el fraile creyó. Desde ese momento fray Ponce trató de rastrear este asunto con mayor profundidad interrogando a otras religiosas que en principio negaban todas las acusaciones pero ante la insistencia del confesor «les hizo creer que habían sido cómplices $»^{35} \mathrm{y}$ ellas acabaron haciendo confesiones voluntarias de juntas diabólicas $\mathrm{y}$ trato con el demonio.

El 31 de marzo de 1764 María de los Dolores Montero revocó las declaraciones anteriores «echando la culpa a su confesor fray Agustín Ponce de haber confesado delitos que no había cometido» ${ }^{36} \mathrm{y}$ también reconoció haber hecho las cédulas de pacto con el demonio por aburrimiento, sin saber escribir, poniendo solo garabatos ${ }^{37}$.

Por otro lado doña María de San Rafael Losada que había contado hechos tan extraordinarios, en su declaración del 24 de septiembre de 1765 y el 3 de octubre del mismo año dio buenas pistas sobre lo que realmente podía estar ocurriendo en el convento. Por un lado acusó de solicitantes ${ }^{38}$ a distintos confesores ${ }^{39}$ a los que nombró ${ }^{40}$ y en la declaración que realizó el 30 de abril de 1766 comenzó a cambiar su versión de los hechos y dijo que había sido influenciada por el padre Prieto para decir aquellas historias que había declarado. Se había preparado con el padre Prieto para hacer aquella delación durante cuatro meses ${ }^{41}$. Como vemos, a las experiencias de esta devota y su imaginación se une el perfeccionamiento de unas declaraciones por parte de un religioso, que lo ajustó al discurso sobre brujería elaborado por la Iglesia para que resultara así más creíble.

Analizada la documentación podemos concluir que en este convento se produjeron durante años desórdenes sexuales entre los miembros de la orden, religiosos y personas ajenas a la misma como Alonso de Osuna entre otros. También hubo acusaciones de solicitaciones que no llegaron a más y se produjo el nacimiento de bebés como "cestillos" en el seno de la orden. Por otra parte las frecuentes charlas sobre el mundo mágico con las monjas más jóvenes en tiempos que no correspondían, generalmente de noche, junto con la insistencia y presión que ejerció el crédulo fray Ponce, así como la forma de pulir los discursos que debían decir por parte del padre Prieto impulsaron a todas estas mujeres a ingeniar hechos relacionados con la brujería, aquelarres, vuelos y unturas. Al recurrir a la explicación del demonio se conseguía justificar un verdadero escándalo que implicaba a estas mujeres pero también a los religiosos, que habían recibido graves acusaciones. 
El dilatado entuerto del caso del convento de Santa Clara no fue el único en el que podemos observar las presiones que ejercieron crédulos confesores por obtener jugosos relatos. Marina Gil Muñoz se delató el 2 de septiembre de 1746 en Benalauría, un pueblo de Málaga. Se la juzgó por pacto explícito con el demonio, comercio carnal con él y diversos hechos de brujería, involucrando esta reo a muchas otras hechiceras. Durante sus declaraciones inculpó de los mismos delitos a Petronila, Isabel Pérez, Inés Gil, Ana Rosa, Ana Lozano, María y Jacinta de Alcalarejo, Leonor María monja descalza de Ronda, Juana María vecina de Ronda y Ana Pérez. Aunque no ha quedado la información detallada de esta delación previa, la reo declaró tres días más tarde, el 5 de septiembre de 1746, para retractarse diciendo ser todo mentira. En ese momento aseguró que las acusaciones que hizo fueron por una parte por ilusiones que le había hecho vivir el demonio aunque también dijo posteriormente que el demonio había hablado por ella. Profundizando en esta causa, la reo manifestó que había sido hija de la confesión del presbítero Matheos y aportó los siguientes datos:

Siendo este que la reo suspiraba en algunas confesiones la decía que sin duda callaba algunas culpas. Que dicho presbítero proponía a sus hijas de confesión le manifestasen fuera de ella cuanto viesen unas en otras y como la reo no tuviese qué decirle fingió lo que se expresa en su delación, pero pensando después en los testimonios que había levantado hizo su retractación ${ }^{42}$.

31 Probablemente este presbítero sospechaba que se llevaban a cabo actos supersticiosos en la localidad y sus alrededores y necesitaba que hubiera una confesión para poder indagar en tales hechos. La insistencia del religioso hacia los fieles pudo ejercer presiones de forma consciente o inconsciente que derivaron en falsas acusaciones. Marina Gil Muñoz se sintió presionada e impelida a describir unos hechos que no había vivido, por lo que se los inventó usando los recursos de la imaginación y del mayor o menor conocimiento popular del discurso supersticioso y demonológico, tratando de contentar al presbítero.

Un nuevo caso de gran resonancia demonológica fue el acontecido en la localidad granadina de Baza. Comenzó la instrucción de la investigación en 1752 con ocasión de haberse localizado a la intemperie el cuerpo de un niño destripado, decapitado y con una mano cortada. Hubo varias personas implicadas a las que se les abrió una causa, encarcelando a la gran mayoría hasta aclarar los hechos. Entre los involucrados estuvieron: Álvaro de Mendoza ${ }^{43}$, Josefa Romero, Manuela conocida como Manuelilla «la gitana», María Antonia Moreno (hija de Antonia Guillén), Joseph Fernández Cachero $^{44}$, Bernarda Vizcaíno ${ }^{45}$, Pedro Sánchez Charidad ${ }^{46}$, María Josefa Tudela ${ }^{47}$ y Antonia Guillén. Todas estas personas fueron acusadas del asesinato de aquel niño y progresivamente cada una ellas fue declarando y apoyando una historia rocambolesca aderezada con importantes tintes de brujería y aquelarres.

Según lo recogido en la causa contra María Tudela, el 9 de noviembre de 1752, una de las testigos, María Antonia Moreno afirmó que don Álvaro de Mendoza había realizado un encargo a la madre de esta, Antonia Guillén ${ }^{48}$. Una noche esperando que se llevase a cabo dicho "encargo" entraron en su casa Josefa Romero y Bernarda Vizcaíno y le trajeron un niño que Antonia Guillén puso boca abajo en sus rodillas.

La reo con una alpargata o espartera fue refregando al niño la boca y cara y dijo a una de las otras pusiese una cazuela para recoger las babas y lágrimas, lo que así practicaron. Que después, porque lloraba el niño pusieron otra cazuela y sacando esta reo un cuchillo, lo degolló, separándole la cabeza del cuerpo, y la sangre que recogieron se echó en una redoma ${ }^{49}$. 

fundamental fue encubrir a toda costa a Álvaro de Mendoza. Sin embargo no todas las implicadas fueron capaces de sosegar la culpa en sus conciencias durante mucho tiempo y acabaron confesando. Entre otras, Josefa Tudela acabó revelando la verdad y cuando le preguntaron quién había hecho el encargo descubrió la identidad de Álvaro de Mendoza ${ }^{52}$. En la causa contra este último se profundizó un poco más en esta macabra historia y se acabó descubriendo que estas mujeres eran vecinas de la villa de Orce, tierras del propio conde, de ahí que al principio tuvieran miedo de declarar contra él, ya que además habían asesinado a dicho niño. El objetivo real no era evitar la acusación de Mendoza, sino encubrir a alguien mucho más influyente: «[...] según resulta de estos autos, don Andrés de Segura, sujeto de poca salud pero de mucho manejo de caudales y negocios, es administrador general de los estados del Conde de Aguilar». Don Andrés, administrador del Conde, se valía de Álvaro de Mendoza para las ventas de grano, arriendos y otro tipo de gestiones. Teniendo el administrador gran influencia sobre las tierras de Orce, de donde procedían las acusadas, estas tuvieron miedo de involucrar a Mendoza y a don Andrés de Segura por las represalias que posteriormente pudiesen recibir.

La declaración de otro testigo, Francisco de Sena, sacó a la luz unos motivos más que razonables para comprender por qué se había orquestado toda esta situación. Según afirmó, se conocía en Baza y sus alrededores que Andrés de Segura utilizó los despojos del niño para curar ciertos accidentes que tenía: «[...] porque es público que a costa de su mucho caudal y como cacique de Orce, ha facilitado con algunos sujetos de mal vivir a quiénes protege judicialmente, que éstos violentamente castren a algunos hombres para medicinarse él mismo». Que además había recibido noticias de que ya se había castrado a un hombre de nacionalidad francesa y a otro que se dedicaba a vender cosas, y que Álvaro de Mendoza era su único confidente y quién manipulaba y organizaba todos los sacrificios ${ }^{53}$. Conociendo los sucesos al completo, el interés de relatar esos hechos tan vinculados con el imaginario demonológico es más que 
significativo. Con el relato de aquellos detalles las acusadas trataron de evitar la justicia civil y la acusación de asesinato, convirtiendo el asunto en un problema de fe. De esta manera deberían ser juzgadas por la jurisdicción inquisitorial, que interpretaron podría asignarles penas menos duras.

Además de usar el imaginario demonológico como vía de escape de otras realidades o de sucumbir a las presiones de los eclesiásticos, otra razón que motivaba los usos de lo mágico fue socorrer las necesidades económicas y personales que sufrían muchos de estos protagonistas. En la Granada del siglo XviII se abrió una causa contra Lucía Escalante. Compareció como testigo María de Orta que dio importantes detalles de la invocación y trato carnal con el demonio que tenían ${ }^{54}$.

Por otro lado, en la causa abierta en 1734 contra esta última ${ }^{55}$, ella misma dijo «que engañada del demonio incurrió en los mismos delitos, dejada de la mano de Dios» ${ }^{56} \mathrm{y}$ decía que sus habilidades procedían de Dios. También detalló respecto a la forma consagrada que tuvo intención de "pisarla y ultrajarla, como desesperada llamó al demonio de todo su corazón y muchas veces renegando de Dios, de su ley y sus sacramentos, ofreciendo su alma al demonio muy de veras ${ }^{57}$.

Tiempo después de contar estas quimeras, María de Orta acudió a su confesor para desahogar su conciencia, habiéndose enterado de que la justicia real pretendía tomarla presa. La situación real de esta mujer fue su pobreza y falta de medios, en opinión de otra testigo: «desnuda y atrasada de medios». Se dedicaba al arte mágico como medio de supervivencia para combatir sus penurias, sin embargo, en su causa se trataron asuntos de conjuros para matar a personas. La situación que debía afrontar esta acusada no era nada fácil y siempre sería mejor ser juzgada por un tribunal inquisitorial que por uno civil ${ }^{58}$. Llegó a realizar hasta diez delaciones voluntarias donde iba montando una verdadera historia con algunos matices del ideario de la brujería, implicando incluso a otras hechiceras, historia que luego acabó desmontando progresivamente. En la causa, tras ir confesando los verdaderos motivos de tales invenciones se recoge que se hallaba «fatigada de hambre» y «pide que como a espontánea se la trate con piedad, que el diablo la ha tenido engañada y que respecto a hallarse dispuesta a hacer confesión general se le dé licencia para la absolución» ${ }^{59}$.

Por estas calendas también se investigó la causa contra Catalina Gutiérrez alias la Genara, natural de Castro del Río y vecina de Cabra, Córdoba. En 1730 en Castro del Río comparecieron tres testigos ante el comisario don Francisco Garrido para denunciar que habían visto a unas mujeres con fama de brujas y a las que le atribuían haber empleado la brujería con un niño de 6 meses $^{60}$. Desde 1730 hasta 1739, cuando compareció la reo, se fueron acumulando testimonios contra Catalina por parte de distintos vecinos. En la audiencia del 20 de mayo de 1739 la reo confesó distintos conjuros, las oraciones que recitaba y los ingredientes que utilizaba mezclando las artimañas supersticiosas con las que se ganaba la vida con discursos de resonancia demonológica. Detalló que invocó a los demonios haciendo un círculo en el suelo con carbón y poniendo dentro pan, queso, una jarra de agua y un cuchillo. Según afirmó estando la sala cerrada con la luz apagada, siendo las doce de la noche vinieron los espíritus en forma de gatos a comerse los trozos de pan y queso ${ }^{61}$. También describió que para hacer una curación necesitó la ayuda del demonio, que se apareció en forma de perro con cuernos y que le pidió a cambio renegar de Dios y tener trato carnal con ella a placer ${ }^{62}$. 

alegando querer revelar hechos que había ocultado maliciosamente. Entre otros declaró que tenía pacto con el demonio y volvió a decir que le había entregado su alma. También se recogió que:

Asistió la reo a la casa de Marina Morales donde estaban otras muchas que esta hechicera, y la maestra Marina Morales tomó unos ungüentos y con unas oraciones que dijo, que no entendió la reo por la mucha gritería que había, entró un hombre que después conoció la reo que era el demonio, y habiéndolas untado dicha Morales a todas las comisuras y cejas, besó la dicha Morales al demonio en la parte posterior y al instante se levantaron del suelo y salieron volando y llegado a la ermita de San Roque extramuros, sin hacer nada se volvieron a casa de la dicha Morales, donde esta las fue limpiando del ungüento diciendo otras oraciones que no entendió la reo ${ }^{63}$.

En este fascinante caso se mezclaron oraciones y conjuros supersticiosos con aparición del demonio, pacto y trato carnal con él, beso en sus partes posteriores, la entrega de su alma, unturas, vuelos nocturnos a aquelarres y actos de brujería a un niño. Estos fueron los hechos descritos por la propia encausada en 1739 pero ya en 1741 su discurso cambió por completo. En dos audiencias diferentes dijo que todo lo anterior era completamente falso. El motivo que tenía esta reo para estas historias «era llevar adelante su mentira y fingirse hechicera [...] y todo fue por llevar la mentira adelante y ver si podía conseguir de la casa de doña Juana Bera las promesas que le tenían hechas» ${ }^{64}$. Insistiendo una y otra vez en que su intención era llevar adelante su ficción y embuste, a partir de ese momento comenzó a desentrañar sus artimañas, contando los trucos y estafas que usaba en distintos conjuros como el conjuro del gusano. Negó el haber realizado actos de brujería al niño de seis meses y haber usado maleficios o tratado con los demonios. Según su testimonio su fin último era socorrer sus necesidades con sus embustes.

Tal y como hemos podido analizar a través de los casos rescatados, lo sagrado y lo profano se mezclaban en la vida cotidiana adoptando distintos significados. Detrás de cada uno de los casos hubo una preocupación fundamental, una razón que movió al individuo a hacer uso de los patrones empleados por el discurso demonológico con un fin determinado. Podemos distinguir entonces una brujería universal creada y reconocida por las clases dominantes de un concepto de brujería de tipo local, basado en las interpretaciones propias que dieron pequeños colectivos a los elementos que habían seleccionado en el discurso oficial, mezclándolos con otros elementos profanos y sagrados. Es así como se dio en el sur de España una configuración singular del ideario europeo de la brujería, eligiéndose en cada caso algunos de los símbolos o prácticas estereotipadas, reconocibles por cualquier grupo social, y transformándolos a partir del imaginario que llegaba a las clases populares. Cada individuo o colectivo personalizaba "a la carta" dichos elementos adaptándolos a su "historia". Esta interacción entre la cultura oficial dominante y la popular fue constante y cambiante, y respondió a la pluralidad de necesidades y de formas de entendimiento propias del variado territorio español.

En una España donde prevalecía la población rural y una educación con sus carencias y ausencias era complicado para la Iglesia poder mantener la rectitud católica de acuerdo a los preceptos y doctrinas emitidos "desde arriba". La mayoría de estos territorios se caracterizaba por la filtración de folclore popular, la continuidad de las tradiciones y de las supersticiones paganas que heredaron del pasado. Estas transferencias unidas a las 
herejías cristianas que pudieran acontecer y a las interpretaciones que la población pudo dar a las ideas teóricas de grandilocuentes teólogos dieron como resultado una mixtura que impulsaba una religiosidad popular que no pocas veces desembocaba en conflictos cotidianos en materia de fe y leyes.

Como se desprende de la casuística analizada, la cultura en general y la brujería europea en particular fueron erigidas de forma viva por todos los estratos sociales. El estereotipo de brujería estuvo en progresión desde la Edad Media hasta quedar plenamente construido para continuar evolucionando, apropiarse y reinterpretarse posteriormente por el pueblo, dando respuesta a necesidades concretas. Estas necesidades no debían ser compartidas por un colectivo completo, sino que podían responder a un individuo o a un grupo reducido en una localidad cualquiera. Es así como se contrapone la imaginería de la brujería, que encontraba en los manuales demonológicos su máxima expresión, a la interpretación que realizaba la población, como hemos analizado en este trabajo.

Mientras los teólogos, demonólogos o sacerdotes fueron trazando el estereotipo intelectual, los individuos de a pie, que no contaban con las herramientas intelectuales para alcanzarlo, modelaron el suyo propio, usándolo a conveniencia para evitar peligros o perjuicios personales. Autoprotegerse de delitos como robo, asesinato, superstición o el desorden sexual o de miedos como el miedo a la hoguera; socorrer sus necesidades económicas o sucumbir a las presiones de curas y presbíteros fueron las causas reales que subyacían en las fabulaciones y quimeras narradas por los protagonistas de estas historias.

El modelo social de brujería europea se presentó como un producto vivo que se caracterizó por su continua fluidez, por contraposición a los estándares fijos que proponía la élite eclesiástica y aristocrática. La interpretación popular de la brujería nunca fue una composición unívoca y cerrada sino una relacionalidad abierta que incluyó procedimientos, símbolos, conocimientos, emociones e intereses. Permaneció en constante construcción sin limitaciones, resultando ser una realidad plural y heterogénea pero completa en significado y en identidad.

\section{BIBLIOGRAFÍA}

AHN, Secc. Inquisición, leg. $1856^{1}$ (sin número de documento).

AHN, Secc. Inquisición, leg. 1856, exp. 8 y 21.

AHN, Secc. Inquisición, leg. $2393^{1}$, s.f.

AHN, Secc. Inquisición, leg. $2393^{2}$, s.f.

AHN, Secc. Inquisición, leg. 2685, exp. 1, 104, 186. 
AHN, Secc. Inquisición, leg. 2690, exp. 66.

AHN, Secc. Inquisición, leg. 2691, exp. 81.

AHN, Secc. Inquisición, leg. 2692, exp. 4, 19, 101, 120.

AHN, Secc. Inquisición, leg. 3723, exp. 4, 125, 129.

AHN, Secc. Inquisición, leg. 3725, exp. 108.

AHN, Secc. Inquisición, leg. 3728, exp. 160.

AHN, Secc. Inquisición, leg. 3736, exp. 105, 107.

AHN, Secc. Inquisición, leg. 4972, pieza 45.

AHN, Secc. Inquisición, lib. 1227, fols. 123-132.

AZURMENDI Mikel \& RAMALLE Enrique (coords.) (2010), Inquisición y brujería: el auto de fe de Logroño de 1610, La Rioja, España: Instituto de Estudios Riojanos.

BLÁzQUEZ Juan (1989), Eros y Tánatos: brujería, hechicería y superstición en España, Toledo, España: Arcan.

CARo Julio (1933), «Cuatro relaciones sobre la hechicería vasca copiadas y anotadas por Julio Caro Baroja», Anuario de Eusko Folklore, 13, 131-145.

CARo Julio (1970), Inquisición, brujería y criptojudaísmo, Madrid, España: Ariel.

CORONAS Luis (1995), «De Zugarramurdi a Rute: una secta brujeril en Andalucía. Lección magistral», comunicación presentada en las Jornadas Académicas, Jaén, Universidad de Jaén, 11-31. Coronas Luis (2000), «Brujos y hechiceros: dos actitudes», M. D. Martínez (coord.), Los marginados en el mundo medieval y moderno, Almería: Instituto de Estudios Almerienses, 239-248.

CoVARRUBIAs Sebastián de (1611), Tesoro de la Lengua Castellana o española, Madrid, España: Luis Sánchez, impresor del rey.

ElLIOT Julián (2005), «Las novias del diablo: la brujería y su represión en la España de la Edad Moderna», Historia y vida, 450, 80-89.

GARCíA Mina (2011), Magia, hechicería y brujería, Sevilla, España: Renacimiento.

GARí Ángel (2012), «Brujería e intolerancia en el norte de España», S. Baches \& A. Gómez (coords.), Miguel Servet, eterna libertad: V centenario de su nacimiento (1511-2011), Huesca: Instituto de Estudios Sijenenses, 345-400.

GIL Alfredo (1999), La Santa Inquisición: sus principales procesos contra la brujería en España, Madrid, España: Edimat Libros.

GINZBURG Carlo (2008 [1989]), «Indicios. Raíces de un paradigma de inferencias indiciales»,

C. Ginzburg, Mitos, emblemas, indicios: morfología e historia, Barcelona: Gedisa, 138-175.

GINZBURG Carlo (1994), «Microhistoria: dos o tres cosas que sé de ella», Manuscrits: Revista d'Història Moderna, 12, 13-42.

GRACíA Rafael (1983), Autos de fe y causas de la Inquisición de Córdoba, Córdoba: Diputación de Córdoba.

GrACíA Rafael (1984), «Un noble cordobés, acusado de brujería: Don Alonso de Aguilar», Boletín de la Real Academia de Córdoba de Ciencias, Bellas Letras y Nobles Artes, 106, 149-190. 
GRACíA Rafael (2001), Brujas y hechiceras de Andalucía, Córdoba, España: Ediciones Gráficas Vistalegre.

HENNINGSEN Gustav (1982), «La brujería en España: el mayor proceso de la historia», Historia 16, 80, 46-53.

HENNINGSEN Gustav (1983), El abogado de las brujas: brujería vasca e Inquisición Española, Madrid, España: Alianza.

HENNINGSEN Gustav (2014), «La inquisición y las brujas», eHumanista: Journal of Iberian Studies, 26, 133-152.

HENNINGSEN Gustav (2020), «De la caza de brujas al culto de brujas», Príncipe de Viana, 81(278), 969-974, <https://dialnet.unirioja.es/descarga/articulo/8036277.pdf>.

LeVACK Brian (1995), La caza de Brujas en la Edad Moderna, Madrid, España: Alianza. (Trabajo original publicado en 1987 como The Witch-Hunt in Early Modern Europe, London, England: Longman.)

PAZ Margarita (2015), «Demonio y mujer: la marca de satán y el combate contra él», Medievalia, $18(2), 325-353$.

PÉREZ Joseph (2010), Historia de la brujería en España, Madrid, España: Espasa.

TAUSIET María (2004), «Avatares del mal: el diablo en las brujas», J. Amelang \& M. Tausiet, El Diablo en la Edad Moderna, Madrid: Marcial Pons, 45-66.

TAUSIET María (2007), Abracadabra omnipotens: magia urbana en Zaragoza en la Edad Moderna, Madrid, España: Siglo XXI.

TORQUEMADA María Jesús (2000), La Inquisición y el Diablo: supersticiones en el siglo XVIII, Sevilla, España: Universidad de Sevilla.

\section{NOTAS}

1. Azurmendi \& Ramalle (2010), Caro (1970), Elliot (2005: 80-89), Gari (2012: 345-400), Gil (1999), Henningsen (1982: 46-53), Henningsen (1983), Henningsen (2014: 133-152), Henningsen (2020: 969-974), Pérez (2010).

2. Coronas (2000: 239-248), Torquemada (2000: 27).

3. AHN, Secc. Inquisición, lib. 1227, fols. 123-132.

4. Este trabajo se enmarca dentro de la microhistoria y se utiliza el paradigma de análisis del indicio. Para ello ténganse en cuenta los siguientes referentes: Ginzburg (1994: 13-42), Ginzburg (2008: 138-175).

5. En ningún caso se ha encontrado el seguimiento de una causa que contenga símbolos o prácticas que respondan exclusivamente al discurso sobre la brujería. Siempre ha sido un híbrido cuya base incluye la superstición tradicional y otros vicios y pecados del mundo terrenal. No se puede hablar de brujería como tal, sino del uso de los elementos reconocibles como propios de la brujería.

6. El Malleus Maleficarum fue la obra de referencia en lo que al aprendizaje en materia de brujería se refiere.

7. AHN, Secc. Inquisición, leg. 2392, s.f. Carta con fecha del 28 de septiembre de 1570 donde los inquisidores de Córdoba Andrés Santos y Antonio Matos de Noroña se comunican con el Consejo de la Suprema y General Inquisición relatando estos hechos. 
8. Según el Tesoro de la Lengua Castellana o española familiar es «el demonio que tiene trato con alguna persona [...] Los que tienen poca conciencia suelen hacer pacto con el demonio y tratar con él familiarmente y por esto los llamaron familiares. Los cuales traen consigo comúnmente en anillos, donde les suelen señalar lo que quieren» (De Covarrubias, 1611: 397).

9. La información extraída de este caso puede consultarse en: AHN, Secc. Inquisición, leg. $1856^{1}$ (sin número de documento).

10. Y posteriormente la hermana de esta última María Magdalena.

11. La documentación deja explícito que si Teodoro Chirinos tenía vivienda se realizara un registro exhaustivo en tales propiedades. No se expresa esa orden para las propiedades de don Alonso de Aguilar.

12. En concreto de brujería habían sido acusados: Mari Jiménez, Andrea de la Cruz, Antonia Sánchez y la viuda de Hernán González y una de sus hijas.

13. AHN, Secc. Inquisición, leg. $2393^{2}$, s.f.

14. Se refleja en la documentación este término haciendo referencia a ser el hombre que cuida de las mujeres que forman parte de la secta de brujos. De hecho él mismo cantaba «yo soy el zanganito, el que las brujas guardo» (Coronas, 1995: 21).

15. Para ver todos los detalles de este insólito caso véase: AHN, Secc. Inquisición, leg. 4972, pieza 45 , fols. 31-36.

16. Los pasajes de los hechizos con los huevos, la descripción del demonio, los instrumentos que tocaban en sus reuniones y la asignación de cada instrumento a cada persona, la orgía sexual, la muerte de la niña y hasta la forma en que se realizaron los vuelos es muy similar a los hechos que se describieron en los procesos de Logroño. Se detalla en el trabajo de Luis Coronas Tejada.

17. Sirva de ejemplo el siguiente testimonio: Julio Caro Baroja rescató una relación elaborada por el historiador guipuzcoano Lope Martínez de Isasti en 1615. Este ejercía el sacerdocio en Rentería, una localidad cercana a Fuenterrabía, lugar donde se había seguido un proceso contra brujas, tras los procesos de Logroño de 1610. Le fue encomendada la tarea de confesar a brujas, que decían había muchas por aquella villa de Renteria y la comarca, y realizó numerosas anotaciones de sus experiencias y memorias. En dicha relación se narra cómo había niños que acudían con frecuencia de noche a aquelarres y una mujer llamada Miruchuloco les asignaba la tarea de guardar los sapos. En dicha relación quedó recogido que un día estando esos niños con otros brujos apareció la Virgen, hermosa y bien ataviada. Llegó lentamente al campo donde se encontraban, les dijo a los niños que estaban siendo engañados y se los llevó (Caro, 1933: 131-145).

18. Respecto a los demás miembros de la secta de brujos, Beatriz Páez quedó clasificada en el margen de su expediente como hechicera y bruja. Murió en prisión durante la investigación de los hechos. Luisa Páez, su hija, también estuvo definida en el margen como hechicera y bruja y acabó suspensa su causa. Francisco Ramos fue puesto en libertad tras advertencias. María Quesada fue absuelta también con advertencias. Ana Gómez no fue apresada ni procesada y no queda reflejada en la documentación la razón de ello. Se recuerda que este caso se encuentra en AHN, Secc. Inquisición, leg. 4972, pieza 45, fols. 31-36.

19. Se ha consultado amplia documentación sobre este caso: AHN, Secc. Inquisición, leg. 2692, exp. 120; leg. 3723, exp. 129; leg. 2690, exp. 66; leg. 2692, exp. 4, 19, 101.

En la investigación de este caso hubo implicadas varias personas, entre ellas el inquisidor y el comisario Zenzano. El inquisidor presenta una postura completamente escéptica de todos los hechos por ser realmente extraordinarios y el comisario veía verdad en las testificaciones de varias de las religiosas.

20. Esta mujer confesó que tenía relación con Alonso de Osuna y que este quiso tener trato ilícito con ella cuando aún no había tomado el estado de monja. Posteriormente, ya formando parte del convento como monja, este siguió insistiendo en visitarla con tal fin. 
21. AHN, Secc. Inquisición, leg. 2692, exp. 120, fols. $5 r$ y v. Para consultar información sobre las marcas que dejaba el demonio en el cuerpo de brujos y brujas véase: Amelang \& Tausiet (2004: 61-62), García (2011: 95), Gracia (2001: 103-104), Henningsen (1983: 80), en esta obra se analizan los casos de brujería de Zugarramurdi y se dan detalles del ritual de iniciación para pertenecer a la secta de brujos. Durante ese ritual el demonio marcaba su cuerpo. Una de las mujeres que entró a formar parte de la secta satánica recibió la marca en forma de la pezuña del demonio, a otra mujer llamada Graciana de Barrenechea le había marcado cortándole parte de la nariz y le hizo unas marcas en los ojos con un objeto de oro (Paz, 2015: 325-353). Recuérdese que los conocedores de brujas, tan populares y utilizados en el norte peninsular, reconocían a tales brujas examinando su cuerpo e identificando las marcas del demonio en senos, muslos, ojos o cualquier otra zona del cuerpo humano.

22. AHN, Secc. Inquisición, leg. 2692, exp. 120, fol. $11 r$.

23. AHN, Secc. Inquisición, leg. 2692, exp. 120, fols. $12 v$ y $13 r$.

24. AHN, Secc. Inquisición, leg. 2692, exp. 120, fol. 5v. También en fol. $11 r$.

25. AHN, Secc. Inquisición, leg. 2692, exp. 120, fol. $6 v$. También hicieron referencia a esas juntas diabólicas las hermanas Casasola, doña María de los Dolores Montero, fol. $9 v$.

26. AHN, Secc. Inquisición, leg. 2692, exp. 120, fol. $13 v$.

27. AHN, Secc. Inquisición, leg. 2692, exp. 120, fol. $6 v$.

28. AHN, Secc. Inquisición, leg. 2692, exp. 120, fol. $7 r$.

29. AHN, Secc. Inquisición, leg. 2692, exp. 120, fol. $7 v$.

30. AHN, Secc. Inquisición, leg. 2692, exp. 120, fol. $8 v$.

31. AHN, Secc. Inquisición, leg. 2692, exp. 120, fols. 9r y $v$.

32. AHN, Secc. Inquisición, leg. 2690 , exp. 66 , fol. $2 v$.

33. AHN, Secc. Inquisición, leg. 2692, exp. 120, fol. 10r.

34. AHN, Secc. Inquisición, leg. 3723, exp. 129, fol. 1 r.

35. AHN, Secc. Inquisición, leg. 3723, exp. 129, fol. $1 v$

36. AHN, Secc. Inquisición, leg. 2692, exp. 120, fol. 12v. No obstante en los años siguientes estando en las cárceles confesó de sí y de cómplices nuevos delitos perseverando en ellos hasta octubre de 1767 y en esta ocasión ya no podía inducirla fray Ponce.

37. AHN, Secc. Inquisición, leg. 2692, exp. 120, fol. $13 r$.

38. En ocasiones durante la confesión tenía lugar el delito de solicitación. Consistía en que el confesor se aprovechaba de su trato cercano con las feligresas. Como conocía sus pecados, durante el acto de la confesión les requería favores sexuales bajo el chantaje de no ser absueltas de sus pecados u otro tipo de abusos y chantajes.

39. En otro documento se trata la acusación de fray Miguel Gómez, fray Miguel Parrilla y fray Félix Marfil como solicitantes, que luego quedaron suspendidas.

40. AHN, Secc. Inquisición, leg. 2692, exp. 120, fol. $7 v$.

41. AHN, Secc. Inquisición, leg. 2692, exp. 120, fol. $8 v$.

42. AHN, Secc. Inquisición, leg. 3728, exp. 160, fol. $2 v$.

43. Su causa se encuentra en AHN, Inquisición, leg. 3736, exp. 105. Natural de Granada, vivía en Orce. Con 19 años fue procesado por mahometano y resuelta su causa.

44. La información de las causas de todos estos acusados está en la alegación fiscal: AHN, Inquisición, leg. 2685, exp. 104.

45. Su causa se encuentra en AHN, Inquisición, leg. 2685, exp. 186.

46. Su causa se encuentra en AHN, Inquisición, leg. 3723, exp. 125.

47. Su causa se encuentra en AHN, Inquisición, leg. 2691, exp. 81.

48. Madre de María Antonia Moreno.

49. AHN, Inquisición, leg. 2691, exp. 81, fol. 1 r.

50. AHN, Inquisición, leg. 2691, exp. 81, fol. $1 r$.

51. AHN, Inquisición, leg. 2685, exp. 104, fol. $3 v$. 
52. AHN, Inquisición, leg. 2691, exp. 81, fol. $1 v$.

53. AHN, Inquisición, leg. 3736, exp. 105, fol. $3 v$.

54. AHN, Secc. Inquisición, leg. 3736, exp. 107, fols. $2 r$ y $v$.

55. María de Orta se delató a sí misma amonestada por su confesor y se le abrió causa para investigar los hechos, pero también actuó como declarante en la causa abierta a otras acusadas.

56. AHN, Secc. Inquisición, leg. 3725, exp. 108, fol. $2 v$.

57. AHN, Secc. Inquisición, leg. 3725, exp. 108, fol. $5 v$.

58. Sobre la mayor rigidez y dureza de las penas de tribunales seglares frente a episcopales e inquisitoriales en España véase: Blázquez (1989: 74-86), Levack (1995: 123), Tausiet (2007: 3-38 y 171), Torquemada (2000: 31-33).

59. AHN, Secc. Inquisición, leg. 3725, exp. 108, fol. $5 v$.

60. AHN, Secc. Inquisición, leg. 3723, exp. 4, fol. $1 r$.

61. AHN, Secc. Inquisición, leg. 3723, exp. 4, fol. $3 r$.

62. AHN, Secc. Inquisición, leg. 3723, exp. 4, fols. $4 r \mathrm{y} v$.

63. AHN, Secc. Inquisición, leg. 3723, exp. 4, fol. $6 v$.

64. AHN, Secc. Inquisición, leg. 3723, exp. 4, fol. $7 r$.

\section{RESÚMENES}

Algunos de los retos a los que tuvo que hacer frente la Inquisición en Andalucía fueron escuchar a personas que aseguraban acudir a aquelarres por la noche, untarse ungüentos que les permitían volar, tener trato carnal con el demonio o reunirse en grupos. Sus autoinculpaciones estaban plagadas de detalles que respondían a los discursos oficiales, al tiempo que mezclaban sus historias con conjuros y oraciones propios de la superstición. Los acusados optaron por utilizar ese aprendizaje popular de lo propio de la brujería para reproducirlo y representarlo intencionadamente con fines particulares, como una vía de escape a las tensiones y a las necesidades cotidianas.

Some of the challenges that the Inquisition in Andalusia had to face were dealing with people who claimed to go to covens at night, smearing ointments that allowed them to fly, having carnal dealings with the devil or meeting in groups. Their self-incriminations were full of details that responded to those official speeches, while mixing their stories with speeches and prayers typical of superstition. The defendants chose to use this popular learning of witchcraft to intentionally reproduce and represent it for particular purposes, as a means of escape from daily stresses and needs.

Certains des défis auxquels l'Inquisition d'Andalousie a dû faire face consistaient à écouter des gens qui prétendaient aller à des sabbats la nuit, à s'enduire d'onguents qui leur permettaient de voler, d'avoir des relations charnelles avec le diable ou de se réunir en groupes. Leurs autoincriminations étaient pleines de détails qui correspondaient à ces discours officiels, tout en mélangeant leurs histoires avec des discours et des prières typiques de la superstition. Les accusés ont choisi d'utiliser cet apprentissage populaire de la sorcellerie pour le reproduire intentionnellement et le représenter à des fins particulières, comme moyen d'échapper au stress et aux besoins quotidiens. 
ÍNDICE

Mots-clés: Inquisition, sorcellerie, superstition, vie quotidienne

Palabras claves: Inquisición, brujería, superstición, vida cotidiana

Keywords: Inquisition, witchcraft, superstition, daily life

\section{AUTOR}

ROCíO ALAMILLOS ÁLVAREZ

Doctorada en Historia Moderna 